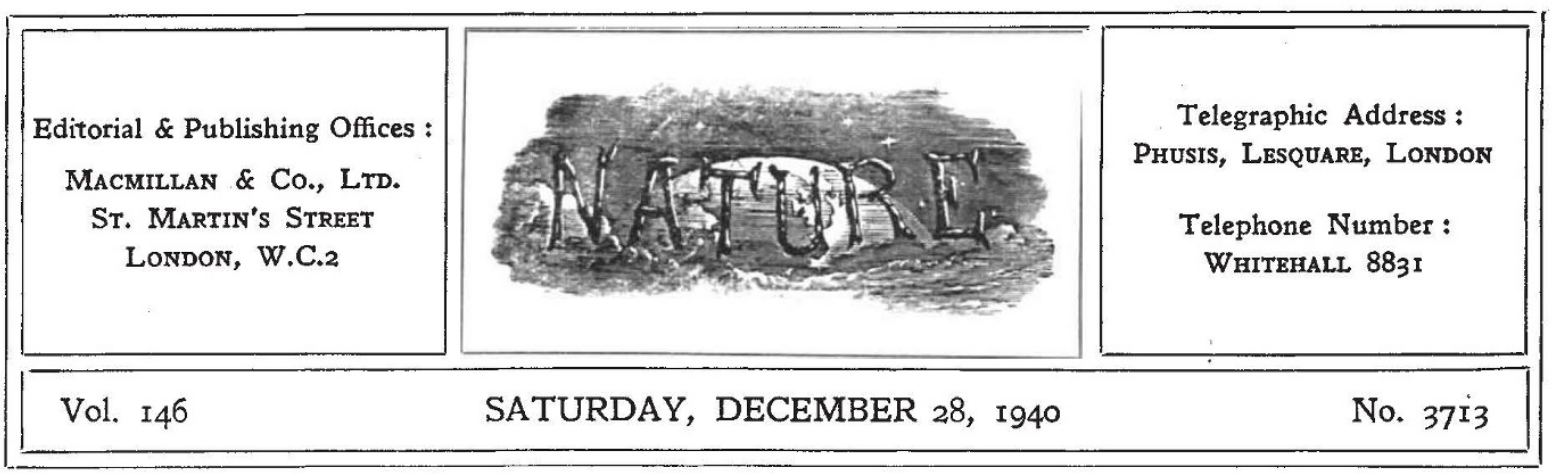

\title{
CULTURAL SIGNIFICANCE OF SCIENTIFIC METHOD
}

$\mathrm{F}^{\mathrm{w}}$ EW things have contributed more to consolidate the unity of the nation and to fortify its resolve to persevere until victory is achieved than the realization that the present struggle is between two fundamentally opposed ways of living between an order in which the individual is crushed and in bondage to a monstrous conception of the State, and an order in which personality is respected, the great traditions of Western civilization are cherished and the human spirit is free to enrich that heritage by further ereative work in art, in literature, in science and other spheres of culture and thought.

Although democracy and totalitarianism are fundamentally opposed ideals, we should not make the mistake of assuming that the democracies have nothing to learn from the totalitarian regime. On the contrary, it is of the utmost importance that there should be a clear understanding of the causes which led to the rejection of democracy, and the emergence of the totalitarian States during the two decades following a war which was to have made the world safe for democracy. Unless we are willing in these fields also to learn from our opponents and to seek to eradicate the weaknesses of democracy as they are brought to light, we may once again experience the frustration which followed the War of 1914-18.

"The serious threat to our democracy is not the existence of foreign totalitarian states. It is the existence within our own personal attitudes and within our own institutions of conditions similar to those which have given a victory to external authority, discipline, uniformity and dependence upon the Leader in foreign countries." This warning of John Dewey in his recent study of "Freedom and Culture" (London: Geo. Allen and Unwin, Ltd., 1940. $7 s .6 d$.) is the more timely when there are already appearing articles even in the technical Press attributing our economic troubles to State interference with private competitive effort for gain, and advocating an immediate return to untrammelled laissez faire.

Whatever may be the nature of the social and world order after the War, it is certain that a return to the position of August 1939 with a minimum of disturbance is both illusory and dangerous. To desire no nobler prospect than a perpetuation of the disparities and injustices, the inertia and complacency of the period 1918-39 is a Maginot complex in the social realm, and treason to the spirit which the nation has displayed in the last nine strenuous months. A hide-bound persistence in methods and doctrines which were sound enough fifty or a hundred years ago may easily prove as costly in the financial, economic and social field as in the field of actual warfare. It might not lose the War ; it would almost certainly once again lose the peace.

A foremost need is an unprejudiced review of conditions as they are now and as they are likely to be after peace has been won, with an open and unprejudiced mind, ready to accept any changes which are shown to be necessary, however unpalatable, and to abandon any preconceptions, however deeply cherished, which have become unpalatable. Even this, however, is not enough. If we are to build an enduring order we must go even deeper. We must establish right relations between democratic institutions and human relations, with all that is understood by culture in the truest and widest sense of the word. 
Democracy, as Sir Richard Livingstone has reminded us, like patriotism, is not enough. It is indeed a way of life and it affords men the best opportunity of leading the good life; but it is no guarantee that they will lead it. We have yet to realize that democracy is a way of personal life and one that provides a moral standard for personal conduct. Unless we can find that moral power, both the value and the very existence of democracy are in peril.

It is well that there should be no mistake as to the tremendous moral or even religious challenge thrown down to democracy at the present time. That internal challenge must be met if the external threat of the totalitarian States is to be overcome, and in his study of freedom and culture Prof. Dewey leaves no room for complacency, for all his confidence as to the ultimate issue. That will be assured so long as we face our problems in detail as they arise, with all the resources provided by collective intelligence in co-operation.

This question of the relation of freedom and democracy to culture involves not merely spiritual and moral issues but also those of science. As Prof. Dewey points out with respect to means for understanding social events, we are still living in the pre-scientific epoch, although the events to be understood are the consequences of the application of scientific knowledge to a degree unprecedented in history. It is this that gives such significance to Mannheim's recent attempt to develop a theory of planning for freedom and the technique of social control. No democracy has ever made complete or adequate use of scientific method in deciding upon its policies, although freedom of inquiry, toleration of adverse views, freedom of communication, and the distribution of what is discovered to every individual as the ultimate intellectual consumer, are involved in the democratic as in the scientific method.

Prof. Dewey's reminder of the potential alliance between scientific and democratic method is indeed timely, and not irrelevant to the organization of our war effort as indicated in a recent leading article (see Nature, Oct. 12, p. 469). When democracy openly recognizes the existence of problems and the need for probing them as problems as its glory, political groups which refuse to admit incompatible or unpalatable opinions will be relegated to the obscurity which is already the fate of such groups in science.

Prof. Dewey has more to say about the interaction of science and society to-day and its relation to the future of democracy. One of the most stimulating chapters of his book is that in which he discusses the relation of science and free culture. We can no longer assume that the assured advance of science will lead to free institutions by dispelling ignorance and superstition: Some of the new powers with which science has endowed mankind, such as the radio and the Press, have proved potent tools of oppression and servitude. The question is raised whether science, like propaganda, can shape ends.

Prof. Dewey gives an admirable survey of the different points of view from which are approached the questions of the extent to which the shaping of science, and the determination of the direction of its advance, are determined by the social environment, and the social responsibilities of the scientific worker. This leads him not merely to raise the question whether a democratic society can exist without regulation, exercised by a public authority on behalf of social unity, of scientific pursuits, but also whether it is possible for the scientific attitude to become such a weighty and widespread constituent of culture as to shape human desires and purposes. This latter question involves the direct issue of the kind of culture in which scientific method and scientific conclusions are integrally incorporated.

It may be argued that one of the reasons why men have been willing to accept conclusions derived from science in place of older ideas has been their serviceability in some aspect of culture or industry. On this ground we might well hold that the kind of serviceability which is capable of generating the highest esteem for science is serviceability for social welfare. The development of economic and agricultural policy in post-War Europe to secure the maximum utilization of scientific knowledge of nutrition might be an important factor of this type in one special field.

The influence of science upon both means and ends is not exercised directly upon individuals but indirectly through incorporation within culture. Moreover, science is not simply a body of conclusions; even more important from a cultural point of view, science is an attitude of mind which resolutely employs certain methods of observation, reflection and test. Scientific inquiry indeed has a morale of its own, including willingness to hold belief in suspense ; ability to doubt until evidence is obtained; willingness to proceed on evidence rather than on a personal preference; ability to hold ideas in solution and use them as hypotheses 
to be tested instead of as dogmas to be asserted; and the enjoyment of new fields for inquiry and of new problems.

As Prof. Dewey points out, each of these traits is contrary to some embedded impulse, and accordingly the mere existence of the scientific attitude and spirit is evidence that science has created a new morale-equivalent to the creation of new desires and new ends-and is capable of developing a distinctive type of disposition and purpose. This service of science may far outweigh its serviceability in the social field. The development of a scientific outlook is of fundamental importance for the preservation of democracy, and the transformation of educational content and method to encourage that development and not the mere inculcation of scientific facts is one of the most pressing problems in education to-day. The fate of democracy is bound up with the spread of the scientific attitude. More important even than the contribution of science to the solution of immediate and practical problems, the scientific attitude is the sole guarantee against wholesale misleading by propaganda. It is the only assurance of the possibility of a public opinion intelligent enough to meet present social conditions.

The democratic extension of the scientific morale in this way until it is part of the usual equipment of the ordinary individual involves moral problems also. The scientific worker must acknowledge his moral responsibility for wider communication of the results of his work to others besides those engaged in specialized research. The need, however, is not for scientific men to become crusaders in special practical causes. It is recognition by scientific workers of their social responsibility for contagious diffusion of the scientific attitude.

That task will not be achieved without abandoning once and for all the belief that science is set apart from all other social interests as if it possessed a peculiar holiness. Without sacrificing professional standards, we must find means of securing that the influence of science and respect for its followers are based, not on a sense of mystery or something apart, but on firm understanding of its outlook and ways of working. Much more than the mere dissemination of the facts ascertained in different branches such as physics, chemistry, biology, geology and the like is required.

Science, through the physical consequences of its technical applications, is determining the relations of human beings, whether individually or in groups, one with another. If it is incapable of developing moral techniques which will also determine these relations, the rift in modern culture may involve the doom of democracy and all the values of civilization. Whether science is capable of influencing the formation of ends for which men strive, or whether it is limited to increasing their power of realizing aims which are formed independently of science, depends on the intrinsic moral potentiality of science. A culture which permits science to destroy traditional values but distrusts its power to create new ones, is a culture which, as Dewey remarks, is destroying itself.

The contribution which science can make to the war effort and to the reconstruction which must follow the War in the physical and material realm is gradually becoming more widely appreciated, even if we have far to travel before its full measure is realized. The chief merit of such publications as "Science in War" (see Nature, July 27, p. 112) is indeed the way in which they direct attention to such possibilities and stimulate thought in that field. The contribution which science can make in the cultural field is equally important but far less widely appreciated even among scientific workers themselves. Prof. Dewey's little study is accordingly the more timely and welcome. If scientific workers are stirred by it to think more deeply upon such issues and to concern themselves with this question of diffusing the scientific outlook, they may well make an all-important contribution both to winning the War and building the peace to follow.

Science requires a tradition of freedom of thought, investigation and teaching such as is inherent in a democratic system, if it is to flourish and exert its creative powers; in the same way, democracy has no less need of the spirit and work of science. While cherishing individual freedom and initiative, the whole democratic system must be rigorously scrutinized; we must approach it in an unprejudiced scientific manner, showing ourselves willing to discard whatever is outworn or has served its purpose, ready to learn even from its opponents and to take pains to incorporate new methods or new ideas while safeguarding those to which its own vitality is due. The fundamental thinking which is a prelude to a closer alliance between democracy and science, as a condition of a new and richer world order of freedom and plenitude, must be undertaken now. It may well issue in an era of creative thought and power in science no less than in those other branches of culture of which democracy is alike nurse and champion. 